\title{
Applying Geographic Information Systems (GIS) for surface condition indicators modeling of a flexible pavement
}

\author{
Mohammed Amine Mehdi ${ }^{1,2,3,}{ }^{*}$, Taoufik Cherradi ${ }^{1}$, Said El Karkouri ${ }^{2}$, and Ahmed Qachar ${ }^{3}$ \\ ${ }^{1}$ Mohammadia School of Engineers, Civil Engineering and Construction laboratory, Rabat, Morocco. \\ ${ }^{2}$ National Center for Road Studies and Research, Ministry of Equipment, Transport, Logistics and Water, Rabat, Morocco. \\ ${ }^{3}$ Moroccan Road Directorate, Ministry of Equipment, Transport, Logistics and Water, Rabat, Morocco.
}

\begin{abstract}
In Morocco, as in all world countries, deteriorating road conditions, increasing traffic loads, and decreasing funds have presented a complex management challenge for the road maintenance and rehabilitation process. Hence the need to assess the condition of the pavement network, decide on maintenance strategies, set rehabilitation priorities and implement a maintenance management system. In this regard, Geographic Information System (GIS) is a powerful tool for managing and analyzing data referenced to a geographic location, especially in the field of road infrastructure where information on pavement sections stored in textual databases can be linked by location and attribute in geographical maps. This paper presents a case study, explores the ability of a GIS to visualize the different levels of surface degradation of flexible pavement through the analysis of GIS surface indicator matrices and the reduction of road databases containing the results of the environmental inspection carried out in 2018 on a $50 \mathrm{~km}$ section of the Moroccan national road number 06 from KP $0+080$ to KP $0+130$, applying the Moroccan method carried out by the Moroccan National Center for Road Studies and Research. These thematic maps can justify a budgetary request for the investment of public funds and help in maintenance decisions.
\end{abstract}

\section{Introduction}

The current and future needs for road data manipulation and geographic information applications are enormous. Indeed, road network management and its optimization are operations complicated to manage with the usual supports such as plans, maps, or photographs. The road management system is based on the phenomenon of the information system currently represented in geographic databases, also called spatial reference in forms that require a diverse process of integration adequate and thoughtful. The use of geographic information systems is characterized by the exchange of data and the circulation of spatial information between actors operating on a territory.

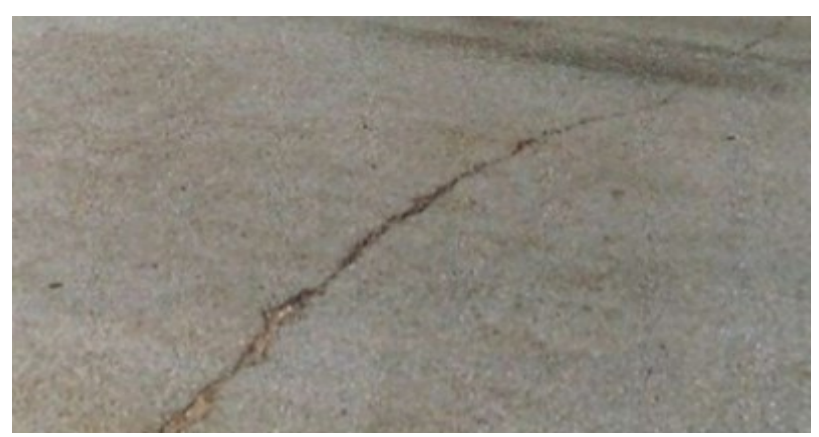

Fig. 1. Cracks

As part of our collaboration with the Moroccan National Center for Road Studies and Research [1], this article will help reduce the effort required in conventional methods to collect and analyze data periodically by reducing repetitive work. The present work analyses the surface deteriorations such as potholes, pullouts, and cracks (Fig. 1, 2, and 3).

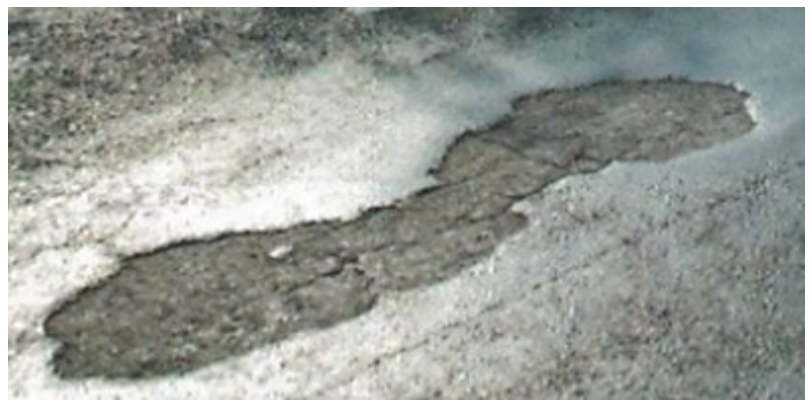

Fig. 2. Pullout

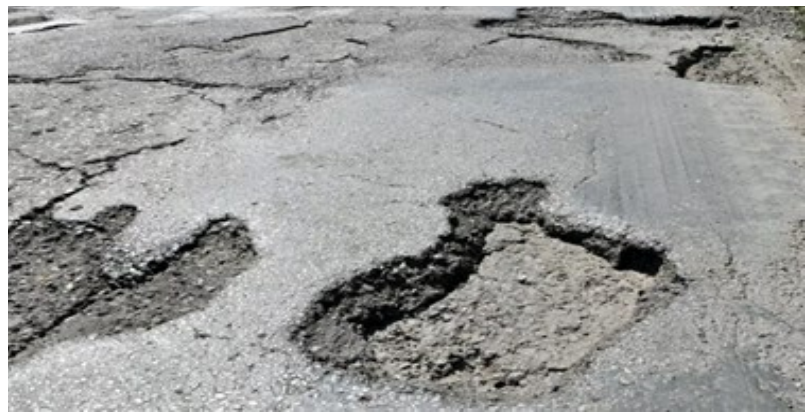

Fig. 3. Potholes

\footnotetext{
* Corresponding author: aminemehdi@ research.emi.ac.ma
} 
The section under study is part of the Moroccan National Road number 06, from KP $0+080$ to KP $0+130$.

Given the geographical location, this road link has known since its birth a high traffic demand estimated at 3.7 Million AADT in 2017. The essential objectives of this article are:

1. Reduce the data of the environmental inspection carried out in 2018 ,

2. Represent the equi-qualities of this pavement according to the surface indicator,

3. Modeling the thematic map by of the surface indicator of this pavement by GIS.[2]

\section{Surface condition indicator (SUI):}

\subsection{Moroccan method}

Every two years based on a visual survey of pavement deteriorations. The visual survey concerns deterioration of the following types: cracks (longitudinal and transverse) [1-3], tears (feathering, peeling, combing, potholes), deformations (rutting, subsidence, etc.), and shoulder slopes. During the same survey, the wearing course nature, the roadway width, shoulders, the traffic class, the nature, and the date of the last intervention are also noted. The principle of the survey is based on the observation at regular intervals of $200 \mathrm{~m}$ of the existence or absence of each type of deterioration, indicating its severity (Fig. 4).

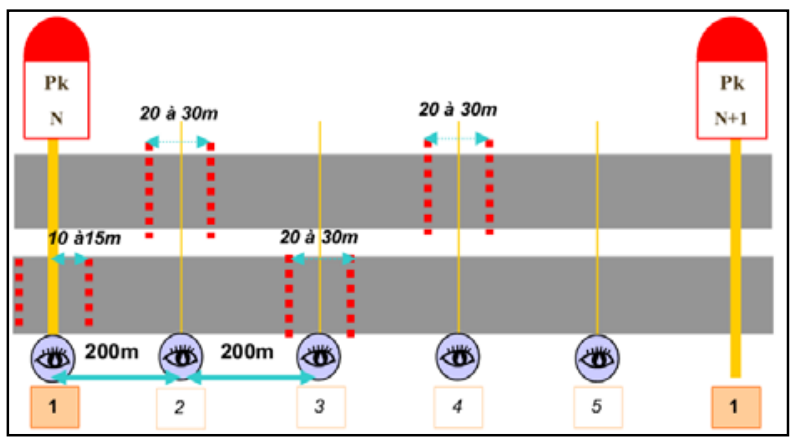

Fig 4. Visual Moroccan inspection method

The integration of the observations is done by adding up the scores given to each of the deteriorations (cracks, pullouts, and potholes) on each $1 \mathrm{~km}$ section.

These indicators characterize $1 \mathrm{~km}$ of road and can have four values:

- A: Good

- B: Acceptable

- C: Poor

- D: Very bad

\section{Materials and methods}

\subsection{Inspection}

For each $\mathrm{km}$ of pavement, the surface distress condition [4] is classified into four classes for each distress according to the following decision grid, based on the cumulative scores over the $\mathrm{km}$ :
Table 1. Matrix of deterioration levels according to their types

\begin{tabular}{|c|c|c|c|}
\hline $\begin{array}{c}\text { Deteriorations } \\
\text { classes }\end{array}$ & $\begin{array}{c}\text { Cracks } \\
\text { (longitudinal } \\
\text { and transversal) }\end{array}$ & Potholes & Pull-out \\
\hline A & 0 & 0 & $0-1$ \\
\hline B & $1-2$ & 1 & $2-3$ \\
\hline C & $3-10$ & $2-4$ & $4-5$ \\
\hline D & $11-20$ & $5-10$ & $6-10$ \\
\hline
\end{tabular}

The pavement surface condition indicator (SUI) for each $\mathrm{km}$ of paved road is determined according to the three classes of deterioration status, according to the following matrix:

Table 2. Surface deterioration matrix

\begin{tabular}{|c|c|c|c|c|c|}
\hline \multirow{2}{*}{ Potholes } & \multirow{2}{*}{ Pullout } & \multicolumn{4}{|c|}{ Deteriorations } \\
\hline & & $\mathbf{A}$ & B & C & D \\
\hline \multirow{4}{*}{ A } & A & $\mathrm{A}$ & $\mathrm{B}$ & $\mathrm{C}$ & $\mathrm{D}$ \\
\hline & B & $\mathrm{A}$ & B & $\mathrm{C}$ & $\mathrm{D}$ \\
\hline & $\mathrm{C}$ & $\mathrm{B}$ & $\mathrm{C}$ & $\mathrm{C}$ & $\mathrm{D}$ \\
\hline & $\mathrm{D}$ & $\mathrm{B}$ & $\mathrm{C}$ & $\mathrm{D}$ & $\mathrm{D}$ \\
\hline \multirow{4}{*}{ B } & A & $\mathrm{B}$ & B & $\mathrm{C}$ & $\mathrm{D}$ \\
\hline & B & B & $\mathrm{C}$ & $\mathrm{C}$ & D \\
\hline & $\mathrm{C}$ & $\mathrm{C}$ & $\mathrm{C}$ & D & D \\
\hline & D & $\mathrm{C}$ & D & D & D \\
\hline \multirow{4}{*}{ C } & A & $\mathrm{B}$ & $\mathrm{C}$ & $\mathrm{C}$ & $\mathrm{D}$ \\
\hline & B & $\mathrm{C}$ & $\mathrm{C}$ & $\mathrm{C}$ & $\mathrm{D}$ \\
\hline & $\mathrm{C}$ & $\mathrm{C}$ & D & $\mathrm{D}$ & $\mathrm{D}$ \\
\hline & $\mathrm{D}$ & $\mathrm{D}$ & $\mathrm{D}$ & $\mathrm{D}$ & $\mathrm{D}$ \\
\hline \multirow{4}{*}{ D } & A & $\mathrm{C}$ & $\mathrm{D}$ & D & $\mathrm{D}$ \\
\hline & B & $\mathrm{D}$ & $\mathrm{D}$ & $\mathrm{D}$ & $\mathrm{D}$ \\
\hline & $\mathrm{C}$ & $\mathrm{D}$ & $\mathrm{D}$ & D & $\mathrm{D}$ \\
\hline & $\mathrm{D}$ & $\mathrm{D}$ & D & D & $\mathrm{D}$ \\
\hline
\end{tabular}

\subsection{GIS method}

Spatial technologies, such as geographic information systems (GIS), are particularly well suited to integrating roadway data and improving the use and presentation of that data for roadway management and operations by using spatial relationships to link geographic and geometric objects and events. To two different degrees, road management problems, such as pavement management, involve relationships between objects and events located in different spatial positions. Road networks span a large area and interact with various land features, including rivers, mountains, buildings, and other roads. Since the data used in the decision-making process have spatial components [5], space technologies appear to be an exciting alternative. Spatial technologies can improve the analysis of several transportation-related issues and improve the quality of the decision-making process.

In this regard, a complete database has been developed from the analysis of the environmental inspection results in three states: 
- Creating a database that represents the following levels of road deterioration: potholes, pullouts, and cracks.

- Representation in the form of a matrix of deterioration subdivided into four levels: A, B, C, and D, to quantify and classify the deteriorations, to provide an image on the evolution of the structural and surface state, to identify the zones of equi-quality classified according to the levels of deteriorations [4], the linear interpolation of the data and translating them into SUI surface indicators.

- Modeling the SUI [2] them in a georeferenced thematic map.

In order to facilitate the reading of the data by the Arcgis software, all the levels of deterioration were transformed into quantitative variables. (Table 3)

Table 3. variable representation

\begin{tabular}{|c|c|}
\hline Surface indicators classes & Reading in ArcGIS \\
\hline A & 1 \\
\hline B & 2 \\
\hline C & 3 \\
\hline D & 4 \\
\hline
\end{tabular}

The modeling of the surface indicators followed several steps on the ArcGIS software:

1. Georeferencing of the map and projection in the Moroccan coordinate system (Fig. 5)

2. Reading of the reduced database (Fig. 6)

3. Projection of the points on the map (Fig. 7)

4. Making the buffer (Fig. 8)

5. Classification by level of surface indicators (Fig. 9)

6. Realization of the thematic map (Fig. 10)

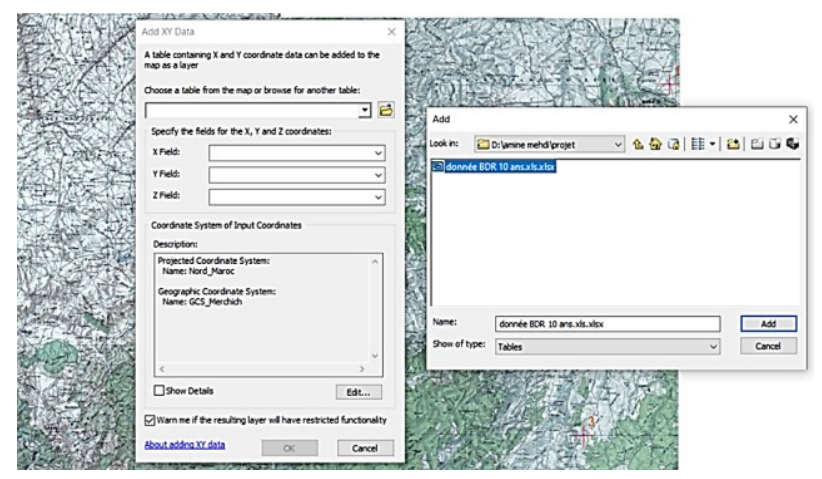

Fig. 5. Georeferencing of the map

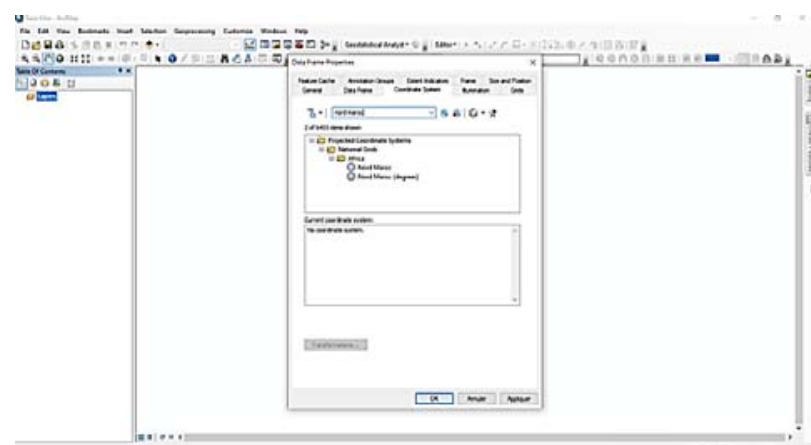

Fig. 6. Data reading

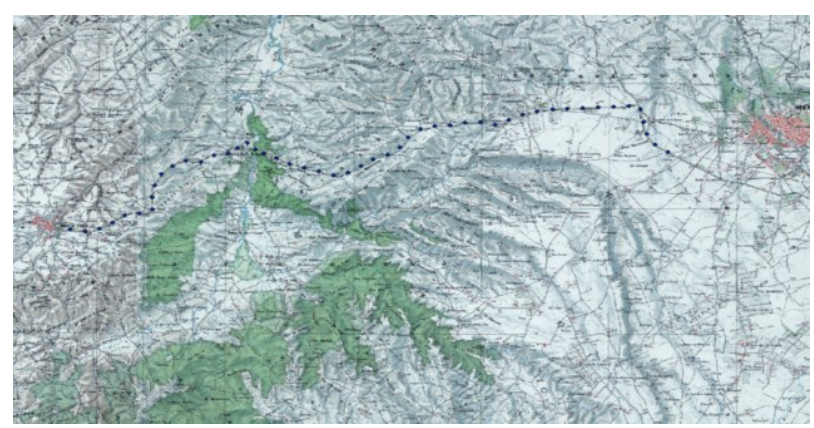

Fig. 7. Points projection

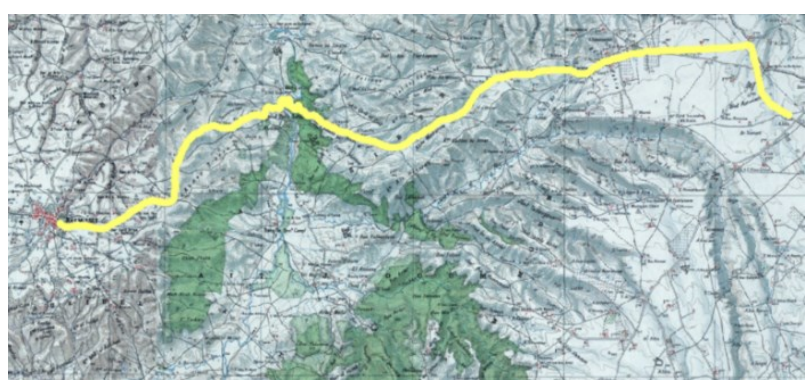

Fig. 8. Buffer

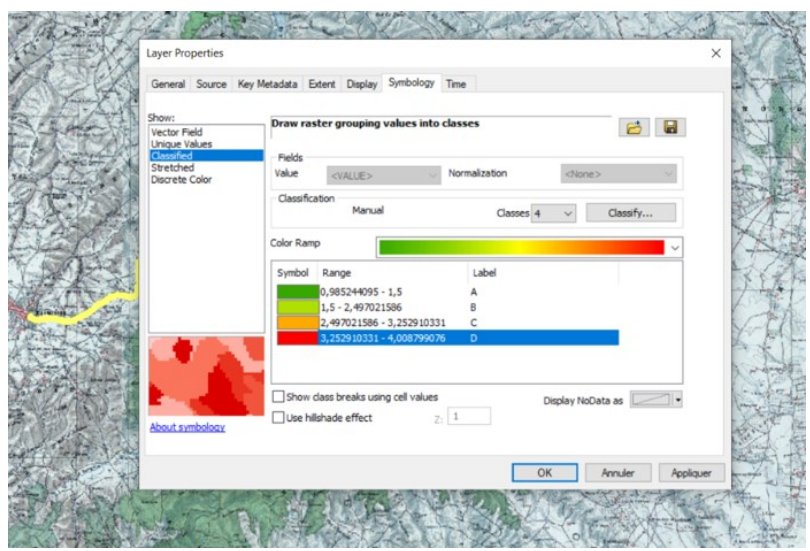

Fig. 9. Classification of indicators

\section{Results and discussion}

Regarding the situation of the national road number 06 , inspections have been carried out in the presence of the administration on a monthly and annual basis. This road has undergone several repair interventions to protect users and ensure a level of comfort and quality on this road axis that has always experienced high demands due to heavy traffic and its attractive geographical location. These interventions include all measures taken by the contractor to ensure the desired level of service by reprofiling, localized resurfacing of shoulders, vegetation control and maintenance of drainage structures, as well as repair of pavement deterioration in order to maintain the level of service, including localized surface dressings and spot repairs including crack sealing and trimming for pavement body repairs.

These parameters are intended to ensure the viability of this roadway link which is open to two-way traffic on a 24-hour basis. According to the analysis of the results obtained in figure 9 , the surface indicators reflect a low 
percentage in $\mathrm{A}+\mathrm{B}$, which means a substantial increase in the number of deteriorations. Despite the interventions which were recommended for this link, the map (Fig:10) represents a strong discontinuity between the various kilometers points as show an imbalance of surface continuation state on the 50 kilometers, the last kilometers while going towards Meknès are the most degraded (indicators of the state $\mathrm{C}$ and $\mathrm{D}$ ).

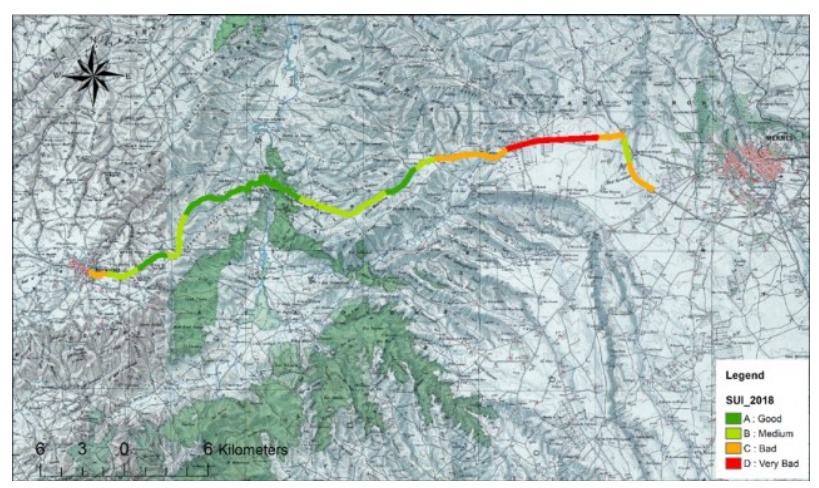

Fig. 10. surface indicators maps (SUI 2018)

\section{Conclusion and perspectives}

In this study, the objective was to model the deteriorations of flexible pavement in the short term (1 year) by applying the Moroccan method to survey the deteriorations, the classification, and the general reading of the general surface condition.

In this perspective, it is still necessary to replan the interventions by introducing a probabilistic prediction of the future deteriorations, by analyzing the evolution of the database, which is the object of the perspectives of the present research, by proposing a model of deterioration by adding other factors such as the evenness, the deflection and the variation of the structural state (STI: structural indicators) and their evolutions in time, in order to propose scenarios of maintenance and maintenance.

\section{Acknowledgment}

I want to thank my dear professor Mr. Toufik Cherradi for his relevant orientations, the National Centre for Road Studies and Research on behalf of Mr. Said El Karkouri, and the Moroccan Road Directorate on behalf of Mr. Ahmed Qachar for their collaboration and availability.

\section{References}

1. M.A.Mehdi, T.Cherradi, M.Quachar, A.Chigr, : Analysis of structural and surface deteriorations of a flexible pavement, based on inspection results using the MCA method. Materials Today Proceedings, Volume 45, Part 8, 2021, Pages 7538-7546.

2. H. A. Elhadi, "GIS, a Tool for Pavement Management," Master's of Science Thesis in Geoinformatics, Royal Institute of Technology (KTH), Stockholm, 2009. [Citation Time(s):1]
3. Lucky Sephumelele, Nkomoa, Sumaiya Amod Desaia, Khoboso Elizabeth Seutloalib, Kabir Yunus Peerbhaya, Timothy Dubec, Assessing the surface material quality of unpaved rural roads to understand susceptibility to surface deterioration. A case study of four rural areas in KwaZulu-Natal, South Africa Volume 112, August (2019), Pages 3-11.

4. Lucky Sephumelele, Nkomoa, Sumaiya Amod Desaia, Khoboso Elizabeth Seutloalib, Kabir Yunus Peerbhaya, Timothy Dubec, Assessing the surface material quality of unpaved rural roads to understand susceptibility to surface deterioration. A case study of four rural areas in KwaZulu-Natal, South Africa Volume 112, August (2019), Pages 3-11.

5. J. Neelam and P. K. Nanda, "Geographical Information System for Pavement Management Systems," Map Asia Conference, India, 2003. 